\title{
Pathology of Idiopathic Pulmonary Fibrosis Assessed by a Combination of Microcomputed Tomography, Histology, and Immunohistochemistry

Naoya Tanabe, ${ }^{* \dagger}$ John E. McDonough, ${ }^{\ddagger \S}$ Dragoş M. Vasilescu, ${ }^{*}$ Kohei Ikezoe, ${ }^{* \dagger}$ Stijn E. Verleden, ${ }^{\S}$ Feng Xu, ${ }^{*}$ Wim A. Wuyts, Bart M. Vanaudenaerde, ${ }^{\S}$ Thomas V. Colby, ${ }^{\natural}$ and James C. Hogg*

From the Centre for Heart and Lung Innovation, * St. Paul's Hospital, University of British Columbia, Vancouver, British Columbia, Canada; the Department of Respiratory Medicine, ${ }^{\dagger}$ Graduate School of Medicine, Kyoto University, Kyoto, Japan; the Department of Internal Medicine, ${ }^{\ddagger}$ Section of Pulmonary, Critical Care \& Sleep Medicine, Yale School of Medicine, New Haven, Connecticut; the Department of Chronic Disease, Metabolism and Aging, ${ }^{\S}$ Laboratory of Respiratory Diseases, KU Leuven, Leuven, Belgium; and the Department of Laboratory Medicine and Pathology, "Mayo Clinic, Scottsdale, Arizona

\author{
Accepted for publication \\ September 1, 2020. \\ Address correspondence to \\ Naoya Tanabe, M.D., Ph.D., \\ Department of Respiratory \\ Medicine, Graduate School of \\ Medicine, Kyoto University, \\ 54 Kawahara-cho, Shogoin, \\ Sakyo-ku, Kyoto, 606-8507, \\ Japan. E-mail: ntana@kuhp. \\ kyoto-u.ac.jp.
}

\begin{abstract}
Idiopathic pulmonary fibrosis (IPF) is a fibrotic disease with the histology of usual interstitial pneumonia (UIP). Although the pathologist's visual inspection is central in histologic assessments, threedimensional microcomputed tomography (microCT) assessment may complement the pathologist's scoring. We examined associations between the histopathologic features of UIP and IPF in explanted lungs and quantitative microCT measurements, including alveolar surface density, total lung volume taken up by tissue (\%), and terminal bronchiolar number. Sixty frozen samples from 10 air-inflated explanted lungs with severe IPF and 36 samples from 6 donor control lungs were scanned with microCT and processed for histologic analysis. An experienced pathologist scored three major UIP criteria (patchy fibrosis, honeycomb, and fibroblastic foci), five additional pathologic changes, and immunohistochemical staining for CD68-, CD4-, CD8-, and CD79a-positive cells, graded on a 0 to $3+$ scale. The alveolar surface density and terminal bronchiolar number decreased and the tissue percentage increased in lungs with IPF compared with controls. In lungs with IPF, lower alveolar surface density and higher tissue percentage were correlated with greater scores of patchy fibrosis, fibroblastic foci, honeycomb, CD79a-positive cells, and lymphoid follicles. A decreased number of terminal bronchioles was correlated with honeycomb score but not with the other scores. The three-dimensional microCT measurements reflect the pathological UIP and IPF criteria and suggest that the reduction in the terminal bronchioles may be associated with honeycomb cyst formation. (Am J Pathol 2020, 190: 2427-2435; https:// doi.org/10.1016/j.ajpath.2020.09.001)
\end{abstract}

Idiopathic pulmonary fibrosis (IPF) is a chronic fibrotic disease characterized by a rapid decline in lung function and poor prognosis. ${ }^{1}$ The American Thoracic Society, European Respiratory Society, Japanese Respiratory Society, and Latin American Thoracic Association guidelines all recommend that the diagnosis and management ${ }^{2}$ be based on an integrative multidisciplinary assessment of clinical information, radiologic assessment, and histopathologic diagnosis, but although diagnosis can be confirmed without histologic assessment in cases that present features of IPF, including honeycomb cysts on high-resolution computed tomography (HRCT), ${ }^{2}$ histologic assessment remains important especially for diagnosing the early stage of IPF and for improving understanding of the pathogenesis of the disease.

\footnotetext{
Supported by a BC Lung Association Dr. K.K. Pump Fellowship (N.T.), a Parker B. Francis Foundation fellowship award (D.M.V.), an FWO postdoctoral fellowship 12G8718N (S.E.V.), and KU Leuven grant C24/18/ 073 (S.E.V.).

N.T., J.E.M., and D.M.V. contributed equally to this work.

Disclosures: None declared.

Current address of N.T., Department of Respiratory Medicine, Graduate School of Medicine, Kyoto University, Shogoin, Sakyo-ku, Kyoto, Japan.
} 
The histopathologic changes in IPF are characterized by patchy dense fibrosis that is often accompanied by honeycomb cyst formation. ${ }^{2}$ Proliferating fibroblasts and myofibroblasts produce collagen in the active regions of fibroplasia, termed fibroblastic foci. ${ }^{3-5}$ In contrast, the infiltration of inflammatory immune cells into fibrotic regions is generally considered to be mild. ${ }^{2}$ However, recent histologic and gene expression analyses have suggested that a B-cell-mediated immune response and lymphoid follicle formation may be associated with fibrosis. $^{6-9}$

The pathologist's visual scoring of UIP and IPF features on lung samples from surgical lung biopsy is essential in histologic assessment. ${ }^{1,2}$ Although the morphometric approach has been less used in the examination of lungs with IPF compared with other lung diseases, such as chronic obstructive pulmonary disease (COPD),${ }^{10-13}$ studies have suggested that alveolar collapse onto the alveolar duct mainly contributes to a reduction in alveolar surface area and impairs diffusion capacity in patients with IPF. ${ }^{14-16}$ Nonetheless, little remains known regarding direct associations between histologic features of UIP and IPF and quantitative morphometric indexes, including the mean linear intercept $(\mathrm{Lm})$, total lung volume taken up by tissue (\%), and alveolar surface density defined as alveolar surface area per lung volume. ${ }^{17}$

The introduction of microcomputed tomography (microCT) has enabled three-dimensional (3D) morphologic assessments of lung tissues that are very difficult to achieve with conventional histologic analysis. ${ }^{12,13,18,19}$ In addition, microCT of frozen air-inflated tissue enables quantitative assessment without shrinkage and physical cutting of tissues. ${ }^{20}$ Mai et al ${ }^{16}$ combined CT, microCT, and histologic assessment, and found that fibrosis and honeycomb cyst formation in IPF extend from the peripheral to the central region of the pulmonary lobules. Furthermore, McDonough et $\mathrm{al}^{21}$ presented preliminary microCT-based analysis of the complex relationship between honeycomb cysts and conducting airways at the American Thoracic Society international conference, which suggested that the honeycomb cyst formation could be a result of airway remodeling. Recently, Verleden et $\mathrm{al}^{22}$ proposed the importance of the small airway disease in IPF by reporting that the numbers of the terminal bronchioles (defined as the last generation of the conducting airways) were reduced in lungs with end-stage IPF compared with control lungs. Collectively, these findings indicate that quantitative morphometric microCT measurements complement the pathologist's visual inspections of lungs with IPF.

The aim of this study was to extend the understanding of the pathology of lungs with UIP and IPF by investigating the relationship between the experienced pathologist's scorings of histologic features, such as honeycomb cysts, and microCT measurements of alveolar surface density, tissue percentage, $\mathrm{Lm}$, and the number of the terminal bronchioles.
A

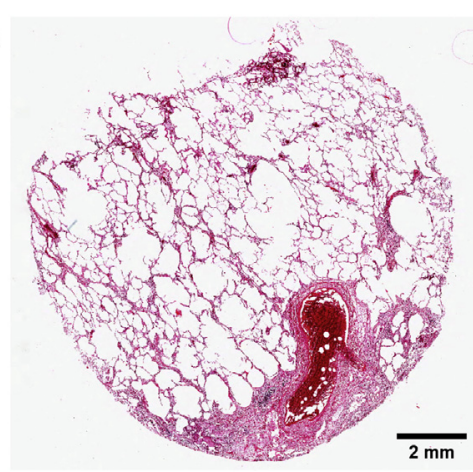

B

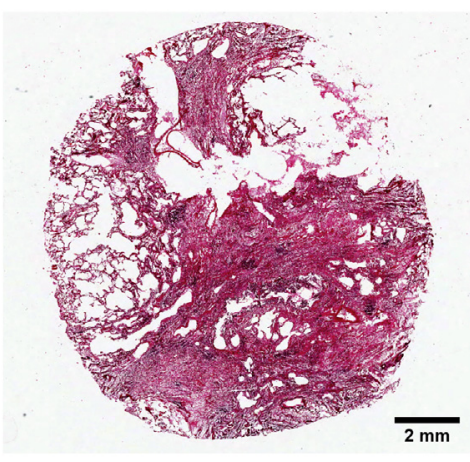

C

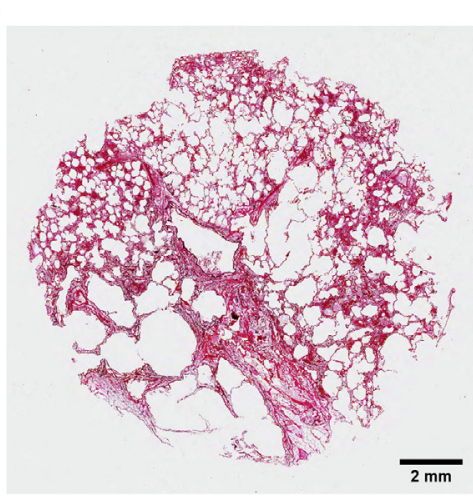

D

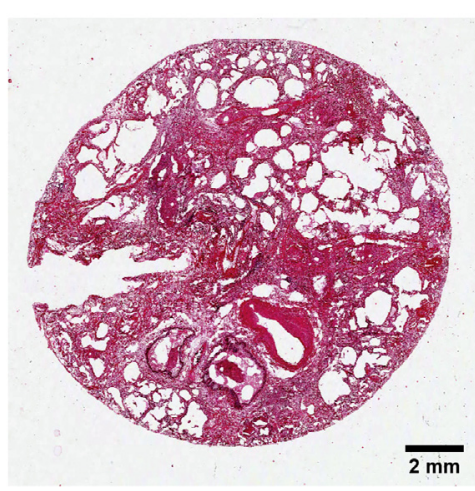

Figure 1 Examples of pathological scores on idiopathic pulmonary fibrosis (IPF) tissue section (hematoxylin and eosin staining). A: Mild patchy fibrosis (score $=1$ ) without honeycomb cysts formation $($ score $=0)$ or emphysema $($ score $=0)$. B: Severe patchy fibrosis (score $=3$ ) without honeycomb cysts formation $($ score $=0)$ or emphysema (score $=0)$. C: Mild patchy fibrosis (score $=1)$ and emphysema $($ score $=1)$ without honeycomb cysts formation (score $=0$ ). D: Severe patchy fibrosis (score $=3$ ) and honeycomb $($ score $=1)$ without emphysema $($ score $=0)$. Scale bars $=2 \mathrm{~mm}$. 
Table 1 Demographic Characteristics of Study Participants

\begin{tabular}{lcc}
\hline Characteristic & Control & IPF \\
\hline Age, y & $58 \pm 10$ & $57 \pm 5$ \\
Height, cm & $175 \pm 6$ & $173 \pm 7$ \\
Weight, kg & $80 \pm 15$ & $73 \pm 10$ \\
Sex, $n$ M:F & $6: 0$ & $10: 0$ \\
Smoking history, $n$ former:never & $2: 4$ & $10: 0$ \\
FEV,$\%$ predicted & NA & $61 \pm 15$ \\
FVC, \% predicted & NA & $59 \pm 20$ \\
DLc0, $\%$ predicted $_{\text {L }}$ & NA & $28 \pm 8$ \\
\hline
\end{tabular}

Data are expressed as means \pm SD unless otherwise indicated. $n=6$ control; $n=10$ IPF.

$\mathrm{D}_{\mathrm{LCO}}$, diffusing capacity for carbon monoxide; $\mathrm{FEV}_{1}$, forced expiratory volume in one second; FVC, forced vital capacity; IPF, idiopathic pulmonary fibrosis; NA, not applicable.

\section{Materials and Methods}

\section{Study Protocol}

A diagnosis of IPF was based on the current American Thoracic Society, European Respiratory Society, Japanese Respiratory Society, and Latin American Thoracic Association guidelines that include dominant airway-centered changes as an exclusion criterion. ${ }^{1,2}$ The major features of this protocol have been described in detail elsewhere. ${ }^{9,22,23}$ Briefly intact lung specimens donated by patients with severe IPF treated by lung transplantation and unused donor lungs that served as controls were inflated with air and frozen solid with liquid nitrogen vapor. The specimen was kept frozen while cutting it into $2-\mathrm{cm}$-thick transverse slices. Two lung tissue samples were obtained from the upper, middle, and lower part of the lung ( $n=6$ per lung) to compare samples with different severity of the disease. .,22,23 $^{2}$ Informed consent was obtained directly from the patient or from the next of kin of the donors who served as controls under conditions approved by the ethical (S52174) and biosafety (MS20101571) committees at the Katholieke Universiteit Leuven and accepted by all the other participating institutions.

\section{microCT-Based Morphometric Quantification}

The tissue samples were kept frozen while scanned at 9.98- $\mu \mathrm{m}$ voxel resolution with a SkyScan 1172 scanner (Kontich, Belgium). ${ }^{22}$ As previously described, ${ }^{9,23}$ image thresholding was applied to separate tissue and airspaces. The tissue segmentation was used to compute tissue percentage and alveolar surface density (defined as alveolar surface area per volume of lung). The airspace segmentation was used to compute the mean airspace size (Lm) by measuring and averaging interalveolar wall distances. ${ }^{22}$ The terminal bronchioles were defined as the last generation of conducting bronchioles and counted manually in the microCT scans of each sample. The number of terminal bronchioles per milliliter of lung was calculated by dividing the number per sample by the sample volume. $^{13,20}$

\section{Histologic Analysis}

The pathologist's scoring was performed in the present study using histologic sections obtained in the previous IPF study. ${ }^{22}$ After microCT, portions of the frozen samples were fixed in alcohol-based formalin at $-20^{\circ} \mathrm{C}$ overnight, warmed to room temperature, and then processed into paraffin blocks from which histologic sections were cut and stained with hematoxylin and eosin and Movat Pentachrome stains. These histologic sections were examined by an experienced pulmonary pathologist (T.V.C.), who scored eight pathological features that consisted of the three major UIP criteria, including patchy fibrosis, honeycomb cyst formation, and fibroblastic foci, as well as five additional pathologic changes, including emphysema, degree of inflammation, hyaline membrane formation, lymphoid follicles, and respiratory bronchiolitis, all on a 0 to $3+$ scale (Figure 1). In addition, other portions of the frozen samples were briefly warmed to $-1^{\circ} \mathrm{C}$, vacuum embedded in the OCT compound (Sakura Finetek, Torrance, CA), immediately returned to $-80^{\circ} \mathrm{C}$, and cut into serial frozen sections (8- $\mu \mathrm{m}$ thick) for immunohistochemistry. These sections were stained with primary antibodies for CD68 (M0876; 1:200 dilution; Dako Cytomation, Carpinteria, CA), CD4 (M7310; 1:200 dilution; Dako Cytomation), CD8 (M7103; 1:400 dilution; Dako Cytomation), and CD79a (M7050; 1:200 dilution; Dako Cytomation) as previously reported. ${ }^{22}$ These sections were also scored by the same pathologist on a 0 to $3+$ scale.

Table2 Comparisons of microCT and Histologic Findings between the Control and IPF Groups

\begin{tabular}{lcc}
\hline Variable & Control & IPF \\
\hline Tissue cores, $n$ & 36 & 60 \\
microCT & & \\
$\quad$ Alveolar surface density, $\mathrm{mm}^{2} / \mathrm{mm}^{3}$ & $15.5 \pm 2.0$ & $8.9 \pm 3.6^{*}$ \\
Tissue, \% & $28.4 \pm 3.7$ & $50.5 \pm 14.2^{*}$ \\
Lm, $\mu \mathrm{m}$ & $360 \pm 53$ & $529 \pm 298^{*}$ \\
Terminal bronchioles in dung, $n / \mathrm{mL}$ & $4.1 \pm 1.6$ & $1.8 \pm 1.3^{*}$ \\
Histologic scoring & & \\
Patchy fibrosis & $\mathrm{NA}$ & $1.3 \pm 1.0$ \\
Fibroblastic foci & $\mathrm{NA}$ & $0.8 \pm 0.8$ \\
Honeycomb & $\mathrm{NA}$ & $0.2 \pm 0.5$ \\
CD68 & $0.7 \pm 0.5$ & $1.6 \pm 0.6^{*}$ \\
CD4 & $0.4 \pm 0.6$ & $1.6 \pm 0.7^{*}$ \\
CD8 & $1.1 \pm 0.4$ & $1.6 \pm 0.6^{*}$ \\
CD79a & $0.1 \pm 0.3$ & $1.2 \pm 0.8^{*}$ \\
Lymphoid follicle & $0 \pm 0$ & $0.8 \pm 0.8^{*}$ \\
\hline
\end{tabular}

Data are expressed as means \pm SD unless otherwise indicated. All scores range from 0 to 3 .

${ }^{*} P<0.005$.

$\mathrm{Lm}$, the mean linear intercept; IPF, idiopathic pulmonary fibrosis; microCT, microcomputed tomography; NA, not available; tissue, $\%$, total lung volume taken up by tissue. 


\section{Statistical Analysis}

Data are expressed as means \pm SD. Statistical analysis was performed with the $\mathrm{R}$ statistical program version 3.4.1 (R Foundation for Statistical Computing, Vienna, Austria; http://www.r-project.org). The Spearman correlation test

A
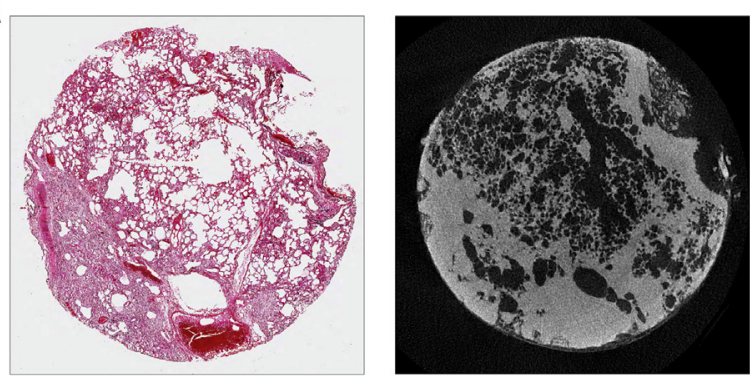

B
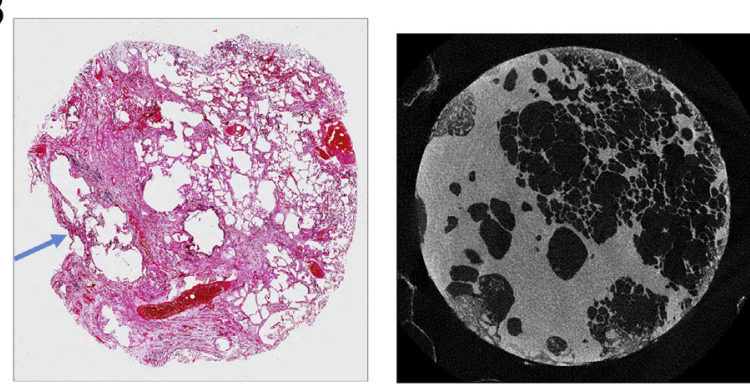

C

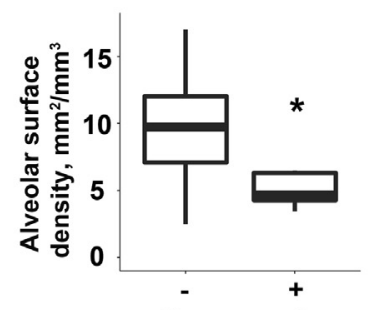

Honeycomb
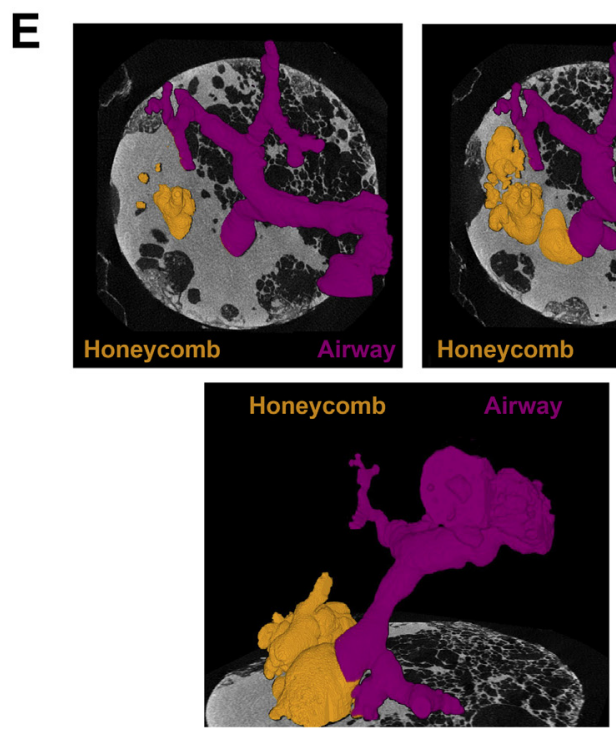

and $U$-test were used for correlation tests and group comparisons, respectively. Multiple comparisons were performed with Wilcoxon tests with Holm correction.

\section{Results}

There is no significant difference in age, sex, height, or weight between the patients with IPF and the controls (Table 1). Table 2 summarizes microCT and histologic scores. Alveolar surface density and the number of terminal bronchioles per milliliter of lung were lower, whereas tissue percentage and $\mathrm{Lm}$ were higher in patients with IPF compared with controls. In addition, CD68-, CD4-, CD8-, and CD79a-positive cells were greater in patients with IPF than controls. The significant difference between the patients with IPF and controls was also present when comparing microCT indexes in the upper, middle, and lower regions separately (Supplemental Figure S1).

Figure 2, A and B gives examples of histologic regions with and without honeycomb formation (score 0 and 1 , respectively) that were registered to the microCTs. The alveolar surface density and number of terminal bronchioles were lower in the honeycomb regions (score $\geq 1$ ) than in the nonhoneycomb regions (score $=0$ ) (Figure 2, C and D). This finding was visualized (Figure $2 \mathrm{E}$ ) and a video that shows a microCT stack of the same sample (Figure 2, B and E) (Supplemental Video S1). The video shows that many branches of the small airway tree (pink) were located in the normal-appearing regions but not in the honeycomb region and that the conducting airway leading into the honeycomb region was directly connected to those severely distorted airspaces (orange). Furthermore, the decreases in the alveolar surface density and number of terminal bronchioles in the honeycomb region were also confirmed in a subanalysis that included nonemphysematous IPF samples (histologic emphysema score $=0$ ) and controls (Figure 3).

Table 3 shows Spearman correlation coefficients between microCT indexes and pathologic scores in IPF samples $(n=59)$. Decreased alveolar surface density and increased tissue percentage and $\mathrm{Lm}$ on microCT were correlated with the histologic scores of patchy fibrosis, fibroblastic foci, and honeycomb. In contrast, a decreased number of the terminal

Figure 2 Comparisons of microcomputed tomographic (microCT) measures between regions with and without honeycomb cysts formation in idiopathic pulmonary fibrosis (IPF) samples (hematoxylin and eosin staining). A: Patchy fibrosis (score $=2$ ) without honeycomb cysts formation (score $=0)$. B: Patchy fibrosis $($ score $=2$ ) with honeycomb cysts formation (score $=1$ ). Arrow indicates honeycomb region. The histologic sections were matched with microCT images. $\mathbf{C}$ and $\mathbf{D}$ : The alveolar surface density and number of terminal bronchioles per milliliter of lung volume on microCT were decreased in honeycomb regions compared with nonhoneycomb regions. E: Three-dimensional rendering of the small airway tree (pink) overlaid onto microCT images from the same stack as used in $\mathbf{B}$ (Supplemental Video S1). The small airway was connected with airspace in the honeycomb region (orange). $n=12$ honeycomb regions; $n=47$ nonhoneycomb regions. ${ }^{*} P<0.05$ versus nonhoneycomb regions. Original magnification, $\times 1(\mathbf{A}, \mathbf{B}$, and $\mathbf{E})$. 

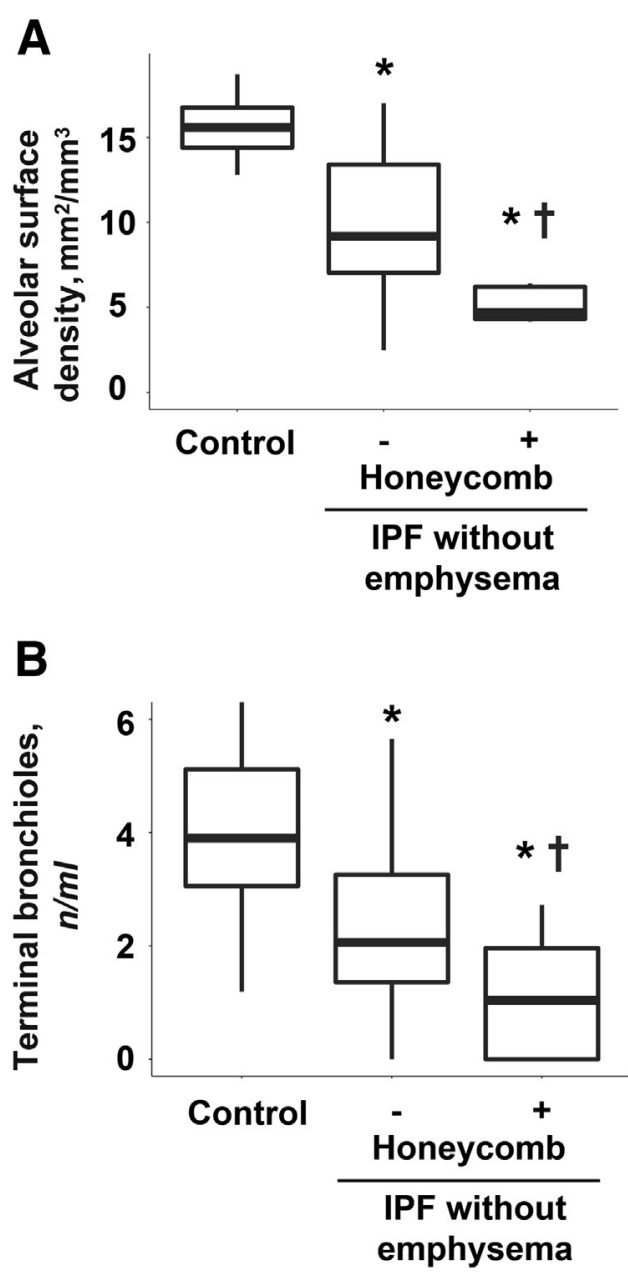

Figure 3 Comparisons of alveolar surface density and number of terminal bronchioles between nonemphysematous regions with and without honeycomb cysts formation. The alveolar surface density (A) and number of terminal bronchioles (B) were compared between control, nonemphysematous idiopathic pulmonary fibrosis (IPF) samples with and without honeycomb regions. The absence of emphysema was determined based on the histologic emphysema score of $0 . n=36$ control; $n=10$ nonemphysematous idiopathic pulmonary fibrosis (IPF) samples with honeycomb regions; $n=23$ nonemphysematous idiopathic pulmonary fibrosis (IPF) samples without honeycomb regions. ${ }^{*} P<0.05$ versus controls; ${ }^{\dagger} P<0.05$ versus nonemphysematous IPF samples without honeycomb regions.

bronchioles was correlated with an increased score of honeycomb but not with patchy fibrosis and fibroblastic foci.

Table 4 shows Spearman correlation coefficients between microCT indexes and scores of lymphoid cells in IPF samples $(n=60)$. Increased tissue percentage was correlated with increased scores for CD68-, CD4-, CD8-, and CD79apositive cells and lymphoid follicles, whereas $\mathrm{Lm}$ and the number of terminal bronchioles were not associated with any of the scores of immune cells and lymphoid follicles.

\section{Discussion}

This study compared standard histopathologic criteria of UIP and IPF and quantitative morphologic measures obtained from microCT. The microCT findings of decreased alveolar surface density and increased tissue percentage were positively associated with the pathologist's scoring of patchy fibrosis, fibroblastic foci, honeycomb formation, infiltration of CD79a-positive lymphocytes, and lymphoid follicle formation. Furthermore, a combination of histologic assessment and the $3 \mathrm{D}$ microCT information revealed that a reduction in the number of terminal bronchioles was associated with honeycomb formation but not with patchy fibrosis or fibroblastic foci. These findings indicate that $3 \mathrm{D}$ morphometric assessment via microCT can be used to complement the pathologist's visual inspection by showing the pathological relationship between the peripheral airways and parenchyma in lungs with IPF.

From a histopathologic perspective, lungs with UIP and IPF characterized by spatially heterogeneous fibrosis with fibroblastic foci and honeycomb lesion, ${ }^{1-3}$ and from a physiologic perspective, lungs with IPF are characterized by impaired diffusion capacity, which affects the mortality. ${ }^{24}$ This structure-function relationship has been explained by multiple morphometric studies that found that a collapse of alveoli onto the alveolar ducts in lungs with IPF leads to a reduction of alveolar surface area. ${ }^{14,15,25}$ However, to the best of our knowledge, no prior report has tested the direct relationship between the pathological UIP and IPF criteria and morphometric assessment of lungs with IPF. Therefore, the close correlations between alveolar surface density, tissue percentage, and the histopathologic scores of UIP and IPF presented here provide an explanation for the clinically relevant impairment in diffusion capacity present in patients with IPF.

The widely accepted hypothesis that IPF is generally a parenchymal disease in which the airways are spared was recently challenged by a microCT-based study that found that a loss of the terminal bronchiole number already occurs in minimal fibrotic regions in lungs with IPF compared with controls. ${ }^{22}$ Because the terminal bronchioles are located in the center of the secondary lobules, these recent microCT findings have raised the question of whether there is an interaction between small airway disease, such as loss of the terminal bronchioles, and parenchymal pathologic findings, such as alveolar collapse. The present study sheds light on this issue with the finding that the loss of terminal bronchioles is associated with honeycomb formation but not with patchy fibrosis, which leads to the conclusion that these might be two separate processes. This finding is consistent with the hypothesis proposed by Evans et $\mathrm{al}^{26}$ that the peripheral airway injury is associated with honeycomb cyst formation independent of fibroproliferation in the parenchyma. In addition, although COPD studies have found a close association between emphysema and a reduction in the terminal bronchioles, ${ }^{13,27,28}$ the reduced number of terminal bronchioles in the honeycomb regions was confirmed even in the subanalysis that excluded IPF samples with emphysema (histological score $\geq 1$ ). 
Table 3 Spearman Correlation Coefficients between Microcomputed Tomography Indexes and Pathological Scores in Idiopathic Pulmonary Fibrosis Samples

\begin{tabular}{|c|c|c|c|c|}
\hline Variable & Alveolar surface density, $\mathrm{mm}^{2} / \mathrm{mm}^{3}$ & Tissue, $\%$ & $\mathrm{Lm}$ & Terminal bronchioles, $\mathrm{n} / \mathrm{mL}$ \\
\hline Patchy fibrosis & $-0.66^{*}$ & $0.69 *$ & $0.41^{*}$ & -0.02 \\
\hline Honeycomb & $-0.53^{*}$ & $0.38^{*}$ & $0.40^{*}$ & $-0.34^{*}$ \\
\hline \multicolumn{5}{|l|}{ Other scores } \\
\hline Emphysema & 0.01 & $-0.56^{*}$ & 0.19 & -0.09 \\
\hline Respiratory bronchiolitis & 0.18 & -0.17 & -0.14 & 0.00 \\
\hline
\end{tabular}

$* P<0.05, * * P<0.005$.

$\mathrm{Lm}$, mean linear intercept; tissue, \%, total lung volume taken up by tissue; UIP, usual interstitial pneumonia.

Furthermore, Supplemental Video S1 portrays the 3D spatial relationship between the small conducting airways and microscopic honeycomb regions, which on the conventional 2D histologic sections would be difficult to detect. The 3D visualization indicates that the conducting airways are directly connected to the air spaces within the honeycomb regions. This finding suggests that the potential airways present within the honeycomb region are remodeled beyond recognition, and the small airways might be an origin of honeycomb cysts in IPF. This concept requires further detailed investigation that is beyond the scope of the present study.

Staats et $\mathrm{al}^{29}$ found that a histologic finding of bronchiolectasis is associated with honeycomb score on HRCT, and Walsh et $\mathrm{al}^{30}$ found that traction bronchiectasis on HRCT is closely associated with fibroblastic foci profusion on histologic analysis. These findings suggest that traction bronchiectasis and honeycombing are part of a continuous spectrum of lung remodeling as noted in clinical observations $^{31}$ and are in line with the present microCT findings that indicate a direct communication between the small airway tree and honeycomb regions in lungs with IPF.

Together with previous findings that the polymorphism in the promoter region of the $M U C 5 B$ gene, which regulates mucin production from bronchiolar epithelium, is associated with the pathogenesis of $\operatorname{IPF}^{26,32}$ and the honeycomb regions are lined with bronchiolar-like epithelium, ${ }^{33}$ we speculate that the terminal bronchiole remodeling might be involved in the honeycomb formation.

This study used a single histologic section for each tissue sample. Although microscopic pathologic findings could vary throughout the tissue sample, it is speculated that within-sample variation is smaller than the intersample variation because the cylindrical tissue samples used in this study are relatively small $(20-\mathrm{mm}$ high and $14-\mathrm{mm}$ in diameter). Moreover, the close correlation between the pathologist's score of patchy fibrosis and the tissue percentage on microCT that was obtained from the entire microCT stack suggests that the single histologic section is sufficiently representative of the pathologic findings of the sample core.

Extensive research indicates that a transition of fibroblasts into synthetic myofibroblast and subsequent deposition of collagen play an important role in the progressive fibrotic process after repeated injuries in IPF ${ }^{34,35}$; however, the role of inflammatory immune cells is not established. Histologic studies have found infiltration of inflammatory immune cells, such as B-cell aggregates, ${ }^{8,36,37}$ whereas clinical trials using immunosuppressive therapy have consistently failed to find the effectiveness in patients with IPF. ${ }^{38}$ A recent study by Verleden et $\mathrm{al}^{22}$ found that the CD79a-positive cell infiltration and lymphoid follicle formation are present even in minimal fibrotic regions of lungs with IPF. The present finding extends this observation by finding an association of lymphoid follicle formation score with increased tissue

Table 4 Spearman Correlation Coefficients between Microcomputed Tomography Indexes and Scores of Infiltrated Inflammatory Immune Cells in Idiopathic Pulmonary Fibrosis Samples

\begin{tabular}{llllr}
\hline Variable & Alveolar surface density, $\mathrm{mm}^{2} / \mathrm{mm}^{3}$ & Tissue, $\%$ & Lm & Terminal bronchioles, $\mathrm{n} / \mathrm{mL}$ \\
\hline CD68 & -0.20 & $0.49^{*}$ & 0.02 & 0.20 \\
CD4 & -0.11 & $0.30^{* *}$ & 0.09 & 0.19 \\
CD8 & -0.17 & $0.41^{*}$ & 0.05 & 0.09 \\
CD79a & $-0.44^{*}$ & $0.53^{*}$ & 0.19 & 0.03 \\
Lymphoid follicle & $-0.41^{*}$ & $0.44^{*}$ & 0.14 & -0.06 \\
\hline
\end{tabular}

${ }^{*} P<0.05,{ }^{*}{ }^{*}<P<0.005$.

$\mathrm{Lm}$, mean linear intercept; tissue, \%, total lung volume taken up by tissue. 
percentage and decreased alveolar surface density and further supports the notion that the persistent adaptive immune response contributes to a fibrotic remodeling process in IPF.

Moreover, an increase in CD68-positive cells was associated with the increased tissue percentage in lungs with IPF. This finding is consistent with the hypothesis that macrophages are mainly involved in the pathogenesis of $\mathrm{IPF}^{39,40}$ but could also in part reflect the smoking history in all patients. Macrophages are subcategorized into functional phenotypes, such as M1 and M2, and play various roles in the lung, including host defense to external insults and wound healing after injury. ${ }^{41}$ Therefore, in addition to staining with CD68 antibody, different approach, such as gene expression profiling and flowcytometry, should be integrated in a future study to explore the pathogenic roles of each macrophage phenotype in IPF.

There are limitations to the present study worth noting. First, all cases with IPF were from former smokers. Because smoking is a major cause of emphysema that is closely associated with the loss of the terminal bronchioles, ${ }^{13,27,28}$ the present finding of a reduced number of terminal bronchioles in IPF might have been affected by smoking. However, no correlation was found between the pathologist's score for emphysema and the number of terminal bronchioles, suggesting that the influence of smokingrelated emphysematous destruction is minimal in this study. Second, the sample number is small, and all cases of IPF were very severe and required lung transplantation. To broaden insights into disease phenotypes, it would be beneficial if the design of future studies would include lung specimen from indiiduals with different stages of IPF as well as different smoking status (ie, both smokers and nonsmokers). Third, the static cross-sectional nature of the study limits causal inferences. Therefore, the present study was not able to test whether patchy fibrosis and honeycomb cyst formation induce infiltration of immune cells in lungs with IPF or if specific immune cells induce a fibrotic process in lungs with IPF.

In conclusion, this is the first study, to our knowledge, to find that quantitative morphometric microCT measurements of alveolar surface density, tissue percentage, and $\mathrm{Lm}$ are closely associated with the general histopathologic scoring of patchy fibrosis, fibroblastic foci, and honeycomb lesions in IPF. These data suggest that microCT measurements provide a reliable structural assessment of lungs with IPF, especially since because established major criteria of UIP and IPF are associated with a reduced alveolar surface area, which potentially impairs diffusion capacity in patients with IPF. Furthermore, the 3D microCT evaluation revealed that honeycomb formation, but not patchy fibrosis, is associated with a greater reduction in the number of terminal bronchioles in IPF. Volumetric microCT-based quantification of the lung structure complements histologic assessment of cellular composition of lungs with IPF, and by combining these methods with subsequent gene expression analysis or single-cell sequencing, it may be possible to identify a novel therapeutic target for this devastating lung disease.

\section{Acknowledgments}

We thank Fanny Chu and Jingwen Pan (Center for Heart Lung Innovation, University of British Columbia) for their assistance in histologic preparation and staining.

\section{Supplemental Data}

Supplemental material for this article can be found at http://doi.org/10.1016/j.ajpath.2020.09.001.

\section{References}

1. Raghu G, Collard HR, Egan JJ, Martinez FJ, Behr J, Brown KK, Colby TV, Cordier JF, Flaherty KR, Lasky JA, Lynch DA, Ryu JH, Swigris JJ, Wells AU, Ancochea J, Bouros D, Carvalho C, Costabel U, Ebina M, Hansell DM, Johkoh T, Kim DS, King TE Jr, Kondoh Y, Myers J, Muller NL, Nicholson AG, Richeldi L, Selman M, Dudden RF, Griss BS, Protzko SL, Schunemann HJ; ATS/ERS/JRS/ALAT Committee on Idiopathic Pulmonary Fibrosis: An official ATS/ERS/JRS/ALAT statement: idiopathic pulmonary fibrosis: evidence-based guidelines for diagnosis and management. Am J Respir Crit Care Med 2011, 183:788-824

2. Raghu G, Remy-Jardin M, Myers JL, Richeldi L, Ryerson CJ, Lederer DJ, Behr J, Cottin V, Danoff SK, Morell F, Flaherty KR, Wells A, Martinez FJ, Azuma A, Bice TJ, Bouros D, Brown KK, Collard HR, Duggal A, Galvin L, Inoue Y, Jenkins RG, Johkoh T, Kazerooni EA, Kitaichi M, Knight SL, Mansour G, Nicholson AG, Pipavath SNJ, Buendia-Roldan I, Selman M, Travis WD, Walsh S, Wilson KC; ATS/ERS/JRS/ALAT Committee on Idiopathic Pulmonary Fibrosis: An official ATS/ERS/JRS/ALAT clinical practice guideline. Am J Respir Crit Care Med 2018, 198:e44-e68

3. Katzenstein AL, Mukhopadhyay S, Myers JL: Diagnosis of usual interstitial pneumonia and distinction from other fibrosing interstitial lung diseases. Hum Pathol 2008, 39:1275-1294

4. Cool CD, Groshong SD, Rai PR, Henson PM, Stewart JS, Brown KK: Fibroblast foci are not discrete sites of lung injury or repair: the fibroblast reticulum. Am J Respir Crit Care Med 2006, 174:654-658

5. King TE Jr, Schwarz MI, Brown K, Tooze JA, Colby TV, Waldron JA Jr, Flint A, Thurlbeck W, Cherniack RM: Idiopathic pulmonary fibrosis: relationship between histopathologic features and mortality. Am J Respir Crit Care Med 2001, 164:1025-1032

6. Bringardner BD, Baran CP, Eubank TD, Marsh CB: The role of inflammation in the pathogenesis of idiopathic pulmonary fibrosis. Antioxid Redox Signal 2008, 10:287-301

7. DePianto DJ, Chandriani S, Abbas AR, Jia G, N'Diaye EN, Caplazi P, Kauder SE, Biswas S, Karnik SK, Ha C, Modrusan Z, Matthay MA, Kukreja J, Collard HR, Egen JG, Wolters PJ, Arron JR: Heterogeneous gene expression signatures correspond to distinct lung pathologies and biomarkers of disease severity in idiopathic pulmonary fibrosis. Thorax 2015, 70:48-56

8. Xue J, Kass DJ, Bon J, Vuga L, Tan J, Csizmadia E, Otterbein L, Soejima M, Levesque MC, Gibson KF, Kaminski N, Pilewski JM, Donahoe M, Sciurba FC, Duncan SR: Plasma B lymphocyte stimulator and $\mathrm{B}$ cell differentiation in idiopathic pulmonary fibrosis patients. J Immunol 2013, 191:2089-2095 
9. McDonough JE, Kaminski N, Thienpont B, Hogg JC, Vanaudenaerde BM, Wuyts WA: Gene correlation network analysis to identify regulatory factors in idiopathic pulmonary fibrosis. Thorax 2019, 74:132-140

10. Tanabe N, Vasilescu DM, Hague CJ, Ikezoe K, Murphy DT, Kirby M, Stevenson CS, Verleden SE, Vanaudenaerde BM, GayanRamirez G, Janssens W, Coxson HO, Pare PD, Hogg JC: Pathological comparisons of paraseptal and centrilobular emphysema in COPD. Am J Respir Crit Care Med 2020, 202:803-811

11. Vasilescu DM, Martinez FJ, Marchetti N, Galban CJ, Hatt C, Meldrum CA, Dass C, Tanabe N, Reddy RM, Lagstein A, Ross BD, Labaki WW, Murray S, Meng X, Curtis JL, Hackett TL, Kazerooni EA, Criner GJ, Hogg JC, Han MK: Noninvasive imaging biomarker identifies small airway damage in severe chronic obstructive pulmonary disease. Am J Respir Crit Care Med 2019, 200:575-581

12. Tanabe N, Vasilescu DM, McDonough JE, Kinose D, Suzuki M, Cooper JD, Pare PD, Hogg JC: Micro-computed tomography comparison of preterminal bronchioles in centrilobular and panlobular emphysema. Am J Respir Crit Care Med 2017, 195: 630-638

13. McDonough JE, Yuan R, Suzuki M, Seyednejad N, Elliott WM, Sanchez PG, Wright AC, Gefter WB, Litzky L, Coxson HO, Pare PD, Sin DD, Pierce RA, Woods JC, McWilliams AM, Mayo JR, Lam SC, Cooper JD, Hogg JC: Small-airway obstruction and emphysema in chronic obstructive pulmonary disease. N Engl J Med 2011, 365: $1567-1575$

14. Coxson HO, Hogg JC, Mayo JR, Behzad H, Whittall KP, Schwartz DA, Hartley PG, Galvin JR, Wilson JS, Hunninghake GW: Quantification of idiopathic pulmonary fibrosis using computed tomography and histology. Am J Respir Crit Care Med 1997, 155: $1649-1656$

15. Lutz D, Gazdhar A, Lopez-Rodriguez E, Ruppert C, Mahavadi P, Gunther A, Klepetko W, Bates JH, Smith B, Geiser T, Ochs M, Knudsen L: Alveolar derecruitment and collapse induration as crucial mechanisms in lung injury and fibrosis. Am J Respir Cell Mol Biol 2015, 52:232-243

16. Mai C, Verleden SE, McDonough JE, Willems S, De Wever W, Coolen J, Dubbeldam A, Van Raemdonck DE, Verbeken EK, Verleden GM, Hogg JC, Vanaudenaerde BM, Wuyts WA, Verschakelen JA: Thin-section CT features of idiopathic pulmonary fibrosis correlated with micro-CT and histologic analysis. Radiology 2017, 283:252-263

17. Hsia CC, Hyde DM, Ochs M, Weibel ER; ATS/ERS Joint Task Force on Quantitative Assessment of Lung Structure: An official research policy statement of the American Thoracic Society/European Respiratory Society: standards for quantitative assessment of lung structure. Am J Respir Crit Care Med 2010, 181:394-418

18. Verleden SE, Vanstapel A, De Sadeleer L, Weynand B, Boone M, Verbeken E, Piloni D, Van Raemdonck D, Ackermann M, Jonigk DD, Verschakelen J, Wuyts WA: Quantitative analysis of airway obstruction in lymphangioleiomyomatosis. Eur Respir J 2020, 56

19. Bourdin A, Gamez AS, Vachier I, Crestani B: LAM is another small airway disease: lessons from microCT. Eur Respir J 2020, 56

20. Vasilescu DM, Phillion AB, Tanabe N, Kinose D, Paige DF, Kantrowitz JJ, Liu G, Liu H, Fishbane N, Verleden SE, Vanaudenaerde BM, Lenburg ME, Stevenson CS, Spira A, Cooper JD, Hackett TL, Hogg JC: Non-destructive cryo micro CT imaging enables structural and molecular analysis of human lung tissue. J Appl Physiol (1985) 2016, 122:161-169

21. McDonough JE, Verleden SE, Verschakelen J, Wuyts W, Vanaudenaerde BM: The structural origin of honeycomb cysts in IPF. Edited by D28 Respiratory Disease Diagnosis: Pulmonary Function Testing and Imaging. American Thoracic Society, 2018. pp. A6388-A

22. Verleden SE, Tanabe N, McDonough JE, Vasilescu DM, Xu F, Wuyts WA, Piloni D, De Sadeleer L, Willems S, Mai C, Hostens J,
Cooper JD, Verbeken EK, Verschakelen J, Galban CJ, Van Raemdonck DE, Colby TV, Decramer M, Verleden GM, Kaminski N, Hackett TL, Vanaudenaerde BM, Hogg JC: Small airways pathology in idiopathic pulmonary fibrosis: a retrospective cohort study. Lancet Respir Med 2020, 8:573-584

23. McDonough JE, Ahangari F, Li Q, Jain S, Verleden SE, HerazoMaya J, Vukmirovic M, DeIuliis G, Tzouvelekis A, Tanabe N, Chu F, Yan X, Verschakelen J, Homer RJ, Manatakis DV, Zhang J, Ding J, Maes K, De Sadeleer L, Vos R, Neyrinck A, Benos PV, BarJoseph Z, Tantin D, Hogg JC, Vanaudenaerde BM, Wuyts WA, Kaminski N: Transcriptional regulatory model of fibrosis progression in the human lung. JCI Insight 2019, 4

24. King TE Jr, Tooze JA, Schwarz MI, Brown KR, Cherniack RM: Predicting survival in idiopathic pulmonary fibrosis: scoring system and survival model. Am J Respir Crit Care Med 2001, 164: 1171-1181

25. Myers JL, Katzenstein AL: Epithelial necrosis and alveolar collapse in the pathogenesis of usual interstitial pneumonia. Chest 1988, 94: 1309-1311

26. Evans CM, Fingerlin TE, Schwarz MI, Lynch D, Kurche J, Warg L, Yang IV, Schwartz DA: Idiopathic pulmonary fibrosis: a genetic disease that involves mucociliary dysfunction of the peripheral airways. Physiol Rev 2016, 96:1567-1591

27. Koo HK, Vasilescu DM, Booth S, Hsieh A, Katsamenis OL, Fishbane N, Elliott WM, Kirby M, Lackie P, Sinclair I, Warner JA, Cooper JD, Coxson HO, Pare PD, Hogg JC, Hackett TL: Small airways disease in mild and moderate chronic obstructive pulmonary disease: a cross-sectional study. Lancet Respir Med 2018, 6:591-602

28. Tanabe N, Vasilescu DM, Kirby M, Coxson HO, Verleden SE, Vanaudenaerde BM, Kinose D, Nakano Y, Pare PD, Hogg JC: Analysis of airway pathology in COPD using a combination of computed tomography, micro-computed tomography and histology. Eur Respir J 2018, 51

29. Staats P, Kligerman S, Todd N, Tavora F, Xu L, Burke A: A comparative study of honeycombing on high resolution computed tomography with histologic lung remodeling in explants with usual interstitial pneumonia. Pathol Res Pract 2015, 211:55-61

30. Walsh SL, Wells AU, Sverzellati N, Devaraj A, von der Thusen J, Yousem SA, Colby TV, Nicholson AG, Hansell DM: Relationship between fibroblastic foci profusion and high resolution CT morphology in fibrotic lung disease. BMC Med 2015, 13:241

31. Piciucchi S, Tomassetti S, Ravaglia C, Gurioli C, Gurioli C, Dubini A, Carloni A, Chilosi M, Colby TV, Poletti V: From "traction bronchiectasis" to honeycombing in idiopathic pulmonary fibrosis: a spectrum of bronchiolar remodeling also in radiology? BMC Pulm Med 2016, 16:87

32. Hunninghake GM, Hatabu H, Okajima Y, Gao W, Dupuis J, Latourelle JC, Nishino M, Araki T, Zazueta OE, Kurugol S, Ross JC, San Jose Estepar R, Murphy E, Steele MP, Loyd JE, Schwarz MI, Fingerlin TE, Rosas IO, Washko GR, O'Connor GT, Schwartz DA: MUC5B promoter polymorphism and interstitial lung abnormalities. N Engl J Med 2013, 368:2192-2200

33. Seibold MA, Smith RW, Urbanek C, Groshong SD, Cosgrove GP Brown KK, Schwarz MI, Schwartz DA, Reynolds SD: The idiopathic pulmonary fibrosis honeycomb cyst contains a mucocilary pseudostratified epithelium. PLoS One 2013, 8:e58658

34. Scotton CJ, Chambers RC: Molecular targets in pulmonary fibrosis: the myofibroblast in focus. Chest 2007, 132:1311-1321

35. Blackwell TS, Tager AM, Borok Z, Moore BB, Schwartz DA, Anstrom KJ, et al: Future directions in idiopathic pulmonary fibrosis research. An NHLBI workshop report. Am J Respir Crit Care Med 2014, 189:214-222

36. Marchal-Somme J, Uzunhan Y, Marchand-Adam S, Valeyre D, Soumelis V, Crestani B, Soler P: Cutting edge: nonproliferating mature immune cells form a novel type of organized lymphoid structure in idiopathic pulmonary fibrosis. J Immunol 2006, 176: $5735-5739$ 
37. Campbell DA, Poulter LW, Janossy G, du Bois RM: Immunohistological analysis of lung tissue from patients with cryptogenic fibrosing alveolitis suggesting local expression of immune hypersensitivity. Thorax 1985, 40:405-411

38. Idiopathic Pulmonary Fibrosis Clinical Research Network, Raghu G, Anstrom KJ, King TE Jr, Lasky JA, Martinez FJ: Prednisone, azathioprine, and $\mathrm{N}$-acetylcysteine for pulmonary fibrosis. N Engl J Med 2012, 366:1968-1977

39. Zhang L, Wang Y, Wu G, Xiong W, Gu W, Wang CY: Macrophages: friend or foe in idiopathic pulmonary fibrosis? Respir Res 2018, 19:170
40. Allden SJ, Ogger PP, Ghai P, McErlean P, Hewitt R, Toshner R, Walker SA, Saunders P, Kingston S, Molyneaux PL, Maher TM, Lloyd CM, Byrne AJ: The transferrin receptor CD71 delineates functionally distinct airway macrophage subsets during idiopathic pulmonary fibrosis. Am J Respir Crit Care Med 2019, 200: 209-219

41. Song E, Ouyang N, Horbelt M, Antus B, Wang M, Exton MS: Influence of alternatively and classically activated macrophages on fibrogenic activities of human fibroblasts. Cell Immunol 2000, 204: $19-28$ 